\title{
Evaluation of Therapeutic Efficacy of Vinpocetine in Adjuvant Induced Arthritis Model in Rats
}

\author{
Azza A Ali*, Asmaa S El-Zaitony and Ekram N Abd Al-Haleem \\ Department of Pharmacology and Toxicology, Al-Azhar University, Cairo, Egypt
}

\begin{abstract}
Introduction: Rheumatoid Arthritis $(R A)$ is an incurable chronic inflammatory disorder. Indomethacin is used for symptomatic management of RA; its long term use is associated with potentially life-threatening deleterious side effects. Vinpocetine is an alkaloid extracted from the periwinkle plant used for treating cerebrovascular disorders with no significant side effects. Recent evidences demonstrate its anti-inflammatory properties.
\end{abstract}

Objective: To evaluate the anti-inflammatory, analgesic and neuroprotective activities of vinpocetine against RA as well as the associated neurological disorders and to investigate its influence on the anti-inflammatory activity of indomethacin in rats.

Methods: Complete Freund's adjuvant induced arthritic rats were treated for 3 weeks with indomethacin (1,2 mg/ $\mathrm{kg}$ P.O.) and/or vinpocetine (20 mg/kg P.O.). Body weight, ankle diameter, arthritic score, serum tumor necrosis factor alpha (TNF- $\alpha$ ) and interleukin one beta (IL-1 $\beta$ ), tissue expression of nuclear factor kappa B (NF-KB) were determined and gait score were assessed. Brain monoamines levels and behavior in the swimming test were also measured. In addition, histopathological examinations of hind paw and brain tissues as well as X-ray examinations of the paw were performed.

Results: Combination therapy of vinpocetine with indomethacin significantly improved analgesic and inflammatory parameters as compared to indomethacin alone. Vinpocetine alone decreased the inflammatory markers in the same extent as indomethacin. In some parameters, vinpocetine has equal effect as the combination therapy. It also decreased swimming time while increased direction score together with increased brain norepinepherine and serotonin as well as serum total anti-oxidant capacity (TAC) level. Histopathological and X-ray examinations supported these results.

Conclusion: Vinpocetine has potent anti-arthritic, anti-inflammatory and anti-nociceptive effects. It also potentiates the anti-inflammatory action of indomethacin. It also improves RA associated depression. Thus, it can be used either alone or in combination with indomethacin to avoid or to decrease the serious side effects of indomethacin and to improve RA associated depression.

Keywords: Rheumatoid Arthritis; Pain management; Neuroprotection; Vinpocetine; Indomethacin; Rats

\section{Introduction}

Rheumatoid Arthritis (RA) is the most common type of inflammatory musculoskeletal disorder [1] in which the quality of life has been reported to be lower than in patients suffering from most of the other non-communicable diseases (NCD) [2]. It is defined as a chronic systematic autoimmune inflammatory disease, characterized by a symmetrical persistent synovitis of the joints of the hands, wrist, feet and knee resulting in tender swelling of joints, pain and limitation in motion as well as morning stiffness [3]. As the disease advances, irreversible tissue damage occurs with bone and cartilage destruction leading to joint deformity and muscle atrophy that may involve all joints of the body [4].

Cytokine production is central to the pathogenesis of RA; it arises from numerous synovial cell populations. However, TNF- $\alpha$ plays a fundamental role through activation of cytokine and chemokine expression as well as expression of endothelial cell adhesion molecules, promotion of angiogenesis, suppression of regulatory $\mathrm{T}$ cells and induction of pain [5]. Similarly, interleukin-6 drives local leukocyte activation and autoantibody production. It mediates systemic effects that promote acute phase responses, anemia, cognitive dysfunction and lipid metabolism dysregulation. The central role of these two cytokines has been confirmed by successful therapeutic blockade of membrane and soluble TNF- $\alpha$ as well as the Interleukin- 6 receptor in patients with RA [6]. Interleukin-1 family cytokines are abundantly expressed in RA; they promote activation of leukocytes, endothelial cells, chondrocytes and osteoclasts [7]. It is well known that, synovial cytokines promote osteoclast differentiation and invasion of the periosteal surface adjacent to articular cartilage [8].

Animal models of arthritis have been used to provide insight into the underlying disease process as well as to identify new targets for drug therapy and the potential new therapeutic agents for RA [9]. These animal models share many features with human RA [10] but they also have some differences [11]. Thus, it is of great importance to select animal models that have similar pathology and/or pathogenesis to human RA, they must also have the capacity to predict efficacy of a given therapeutic agent in humans. Adjuvant arthritis in rats has been previously described [12] and was found to be exhibit many similarities to human RA [13]. It is the first model of polyarthritis induced in rats that widely used for evaluation of various anti-arthritic agents [12]. Induction of adjuvant disease can be done with Freund's complete (CFA) [14] which has been considered for several decades as the most effective adjuvants available for raising antibodies in test animals [15].

${ }^{*}$ Corresponding author: Azza A Ali, Prof. and Head of Pharmacology and Toxicology Department, Faculty of Pharmacy, Al-Azhar University, Cairo, Egypt, Tel: +20 01061905439; E-mail: azzamoro@gmail.com

Received May 29, 2016; Accepted June 17, 2016; Published June 24, 2016

Citation: Ali AA, El-Zaitony AS, Al-Haleem ENA (2016) Evaluation of Therapeutic Efficacy of Vinpocetine in Adjuvant Induced Arthritis Model in Rats. J Pain Manage Med 2: 115

Copyright: ( 2016 Ali AA, et al. This is an open-access article distributed under the terms of the Creative Commons Attribution License, which permits unrestricted use, distribution, and reproduction in any medium, provided the original author and source are credited. 
Indomethacin (indo) is one of the nonsteroidal anti-inflammatory drugs (NSAIDs) [16]. It belongs to a group of drugs called indoleacetic acids; it was introduced for the treatment of RA, degenerative joint diseases, ankylosing spondylitis, gout, acute musculoskeletal disorders, inflammation and oedema following surgical technique as well as pain associated with primary dysmenorrhoea [17]. Many RA patients require daily drug treatment for adequate symptomatic relief. Large doses of indo mainly given at night have been found to be effective in relieving the morning pain and stiffness which are such prominent features of active RA [18]. However, the use of NSAIDs in RA is currently limited due to the high risk of gastrointestinal complications in addition to causing renal and cardiovascular complications like acute kidney failure, hypertension, electrolyte abnormalities, myocardial infarction, and stroke [19].

Vinpocetine (vinpo) is a synthetic ethyl ester of the alkaloid apovincamine, which is isolated from the leaves of Vinca minor, commonly known as the lesser periwinkle [20]. It is approved by the European and British Pharmacopoeias [21]. It was initially discovered, developed and marketed under the trade name Cavinton ${ }^{\oplus}$ [22]. Since then, vinpo has been widely used in many countries for the prevention of cerebrovascular disorders and cognitive impairment including stroke, senile dementia and memory disturbances [23]. It is sometimes called a nootropic, meaning cognition enhancer. In the United States of America, vinpo is available in the market as a dietary supplement [24]. It also has potent anti-inflammatory effects via phosphodiasterase-1independent inhibition of NF- $\mathrm{kB}$ signaling and the production of proinflammatory cytokines, such as IL- $1 \beta$ and TNF- $\alpha$ [25] and suppressing the inflammatory responses both in vitro and in vivo [26]. Many studies identify vinpo as a unique anti-inflammatory agent that may be repositioned as a therapeutically agent for the treatment of various human inflammatory diseases [25]. Compared to the traditional steroids and NSAIDs; vinpo has no known significant side effects and can be considered as an attractive alternate anti-inflammatory agent especially for long term use [27].

Consequently, it could be hypothesized that vinpo may be useful for the treatment of RA due to its well established anti-inflammatory effects in addition to being safe and having no harmful adverse reactions. Also, it is expected that its neuroprotective effects on the brain especially antidepressant activity may be helpful in counteracting the associated depression in rheumatic patients especially for elderly and in the late stages of the disease. In contrast, indo has some neurological side effects including mood disturbances which may worsen the case [28].

\section{Materials and Methods}

\section{Drugs and chemicals}

Indomethacin powder was purchased from Misr Co. for Pharmaceutical and Chemical Industries, Cairo, Egypt. It was freshly suspended in tween 80 and daily given P.O. in a dose of $1 \mathrm{mg} / \mathrm{kg}$ [13] and $2 \mathrm{mg} / \mathrm{kg}$ [29] at a dose volume not exceeding $0.5 \mathrm{ml} / 100 \mathrm{~g}$ body weight for 21 consecutive days. Vinpo was purchased as white powder from Sigma-Aldrich Co. (USA). It was freshly suspended in tween 80 and daily given P.O. in a dose of $(20 \mathrm{mg} / \mathrm{kg})$ [30]. CFA was purchased from Sigma-Aldrich Co. (USA). CFA consists of a mixture of heatkilled Mycobacterium tuberculosis suspended in sterile mineral oil $(1 \mathrm{mg} / \mathrm{ml})$. All other chemicals and solvents were of the highest grade commercially available.

\section{Animals}

The study was performed in accordance with the ethical guidelines of the Research Ethics Committee, Faculty of Pharmacy, Al-Azhar University, Egypt. Fifty-six adult Sprague-Dawley male rats, weighing $160 \mathrm{~g}$ to $200 \mathrm{~g}$ at the beginning of the study were obtained from The Nile Co. for Pharmaceuticals and Chemical Industries, Cairo, Egypt. The animals were kept in an air conditioned atmosphere and were kept on standard diet and water ad libitum; standard diet pellets (ElNasr Chemical Co., Abu Zaabal, Cairo, Egypt) contained not less than $20 \%$ protein, $5 \%$ fiber, $3.5 \%$ fat, $6.5 \%$ ash in addition to the vitamin mixture. Rats were allowed to have seven days' acclimation before any experimentation. Rats were housed in stainless-steel cages (four/cage) and food was placed in the sawdust inside the cage to minimize the need for animals to make any potentially painful movement to obtain food. They were taken to test situation one hour before each experiment for adaptation after removing food and water from the home cages. Experiments were usually carried out at a fixed time around $9 \mathrm{AM}$ to 3 PM.

\section{Experimental design}

Fifty-six male Sprague-Dawley rats were randomly classified into seven groups (eight/each) and treated for three weeks as follows:

Group 1: Control rats; normal rats received saline daily for 21 consecutive days.

Group 2: Arthritic rats (RA group); rats were injected by CFA $(0.1 \mathrm{ml} \mathrm{S.C.})$ in the sub-planter region of the left hind paw on day $(0)$ followed by two intra-dermal injections of CFA $(0.1 \mathrm{ml})$ into the root of the tail, one on the same day and the other on the following day.

Group 3 and 4: Indo either low dose (ld) or high dose (hd) treated arthritic rats respectively; in which arthritis was induced in rats then arthritic rats received indo ( 1 or $2 \mathrm{mg} / \mathrm{kg}$ P.O.) daily from day 1 till the end of the experiment.

Group 5: Vinpo treated arthritic rats; in which arthritic rats received vinpo (20 mg/kg P.O.) daily from day 1 till the end of the experiment after arthritis was induced.

Group 6 and 7: Vinpo and either indo low dose (ld) or high dose (hd) treated arthritic rats respectively; in which arthritic rats received combination of vinpo (20 mg/kg P.O.) and indo (1 or $2 \mathrm{mg} / \mathrm{kg}$ P.O.) daily from day 1 till the end of the experiment.

The induction of adjuvant induced arthritis was done according to method earlier described [12] and modified [31]. Rats were injected by CFA $(0.1 \mathrm{ml} \mathrm{S.C.)}$ at a concentration of $1 \mathrm{mg} / \mathrm{ml}$ into the planter surface of the left hind paw on day 0 . In order to enhance the systemic effects of the adjuvant, two additional intra-dermal injections of CFA $(0.1 \mathrm{ml} \mathrm{S.C.})$ were injected into the root of the tail; one on the same day and the other on the following day. All treatments were started the day after the induction of arthritis. Physical parameters and swimming test were performed during the $21^{\text {st }}$ day. X-ray examination of the paw was made on $18^{\text {th }}$ day. At the end of the experiment, blood samples were collected from retro-orbital sinus plexus of rats; serum samples were immediately separated by centrifugation at 1000 RPM for 10 min and then stored at $-50^{\circ} \mathrm{C}$. Then rats were sacrificed under sodium phenobarbital anesthesia (50 mg/kg I.P.) [32] and tissues of hind paw and brain were isolated and stored in $10 \%$ formalin solution. All efforts were made to minimize animals suffering.

\section{Assessment of arthritis}

The progression of CFA induced arthritis was evaluated on days 0 , $1,3,6,8,10,13,15,17$ and 21 after adjuvant injection. Arthritic score was used as a semi-quantitative parameter of polyarthritis severity 
through a well-established, widely used scoring system [33]. Paws were examined and graded for severity of erythema and swelling using a 5 -point scale: $0=$ no signs of inflammation; $1=$ swelling and erythema of the digit; $2=$ moderate swelling and erythema; $3=$ severe swelling and erythema of the limb and $4=$ severe swelling, erythema, gross deformity and disability to use the limb. Ankle diameter was determined by measuring the anterior-posterior diameter, using Vernier caliper which is accurate to $0.02 \mathrm{~mm}$ [34]. Pre-injection values for ankle diameter were measured just prior to adjuvant injection for each rat and used as baseline, two measurements were carried out each time for each rat and the average value was used. The severity of arthritis pain was measured using gait scoring system as a semi quantitative parameter from 0 to 3 : $0=$ normal gait; $1=$ =with slight lameness; $2=$ lameness with weight bearing on toes only and $3=$ non weight bearing animals [35].

\section{Swimming test}

The swimming test was carried out according to the established method and its modification [36]. The test depends on measuring the latency time: time taken until the animal decides to swim; the swimming time: time needed to reach the ramp as well as the determination of the direction score.

\section{$\mathrm{X}$-ray examination}

On the $18^{\text {th }}$ day, rats were anaesthetized with sodium phenobarbital anesthesia $(50 \mathrm{mg} / \mathrm{kg}$ I.P.) at a dose volume not exceeding $0.4 \mathrm{ml}$. the anesthetized rats were kept on a table and X-ray image in the posterioranterior view was obtained and were scanned using a digitizer [32].

\section{Assessment of inflammatory markers}

Both IL-1 $\beta$ and TNF- $\alpha$ level in hippocampus tissue homogenate were assessed using RayBio1 Rat IL- $1 \beta$ and RayBio1 Rat TNF- $\alpha$ ELISA Kits (Ray Biotech, Inc., USA). The steps were carried out according to the manufacturer's instructions.

\section{Assessment of total antioxidant capacity (TAC)}

Total antioxidant capacity in serum samples according to standard methods [37] using commercially available kits (Spectrum diagnostics, Cairo, Egypt). The results were expressed as $\mathrm{mmol} / \mathrm{l}$.

\section{Assessment of monoamines levels}

Determination of brain serotonin, noradrenaline and dopamine was carried out using high performance liquid chromatography (HPLC) system, Agilent technologies 1100 series, equipped with a quaternary pump (Quat pump, G131A model). Separation was achieved on ODS reversed phase column $(\mathrm{C} 18,25 \times 0.46 \mathrm{~cm}$ i.d. $5 \mu \mathrm{m})$. The mobile phase consisted of potassium phosphate buffer/methanol $97 / 3$ (v/v) and was delivered at a flow rate of $1 \mathrm{ml} / \mathrm{min}$. UV detection was performed at 270 $\mathrm{nm}$ and the injection volume was $20 \mu \mathrm{l}$ [38].

\section{Immunohistochemical detection of tissue NF- $\mathrm{BB}$ p65}

Paraffin embedded paw tissue sections of $3 \mu$ thickness were rehydrated first in xylene and then in graded ethanol solutions. The slides were then blocked with $1 \%$ bovine serum albumin in tris buffered saline or phosphate buffered saline ( $\mathrm{pH} 7.4$ ) for $2 \mathrm{~h}$ as appropriate. The sections were then immune stained with primary antibodies; rabbit polyclonal IgG to rat NF-kB p65 (Santa Cruz Biotech, inc., USA) at a concentration of $1 \mathrm{mg} / \mathrm{ml}$ in tris buffered saline. After washing the slides with the appropriate buffer, the sections were incubated with goat anti-rabbit IgG secondary antibody. Sections were then washed again and incubated for $5 \mathrm{~min}$ to $10 \mathrm{~min}$ in a solution of $0.02 \% \mathrm{di}$-aminobenzidine containing $0.01 \% \mathrm{H}_{2} \mathrm{O}_{2}$. Counter staining was performed using Hematoxylin, and the slides were visualized under a light microscope [39]. The quantification of NF- $\mathrm{kB}$ staining was performed by using Leica MDLSD image analysis software. It was represented as the optical density of stained sections per field.

\section{Histopathological examinations of hind paw and brain tissues}

Hind paw and brain from different groups were excised, fixed in $10 \%$ formalin, decalcified in formic acid, embedded in paraffin blocks from which $5 \mu$ thick sections were obtained. Sections were stained with Hematoxylin and Eosin dye, and then evaluated under light microscope. Examinations were done according to the established method [40].

\section{Data analysis and statistical procedures}

Data are represented as mean \pm standard error of the main (SEM). Statistical analysis was performed using one-way analysis of variance (ANOVA) followed by Tukey-Kramer as a post hoc test for multiple comparisons. The 0.05 level of probability was used as the criterion for significance. The data of physical parameters were statistically analyzed by two-way ANOVA followed by Bonferroni test using SPSS version 19.0 program. Analysis of data and presentation of graphs were performed using Graph Pad Prism software version 5 (ISIH software, USA).

\section{Results}

\section{Changes in physical parameters}

On the following day after arthritis induction, all of arthritic rats showed a significant arthritis and hyperalgesia as compared to normal control group manifested as significant increase in all arthritic parameters; Body weight (BW), ankle diameter, arthritis score and gait score. Comparison between different groups regarding BW changes revealed that there was a significant increase in BW of the treated group with either indo (hd), vinpo alone or combined with indo (ld or hd) by $127 \%, 133 \%, 134 \%$ and $135 \%$ respectively as compared to non-treated RA group (Figure 1A). However, comparison between different groups regarding ankle diameter changes revealed that beginning on day 6 , there was significant decrease in ankle diameter of all the treated rats with either indo (hd), vinpo alone or combined with indo (ld or hd) which continued till reaching $92 \%, 87.5 \%, 84 \%$ and $84.3 \%$ respectively as compared to non-treated arthritic rats (Figure 1B). Concerning the effect on arthritis index, Comparison between different groups revealed that concurrent treatment of arthritic rats with indo and vinpo showed a significant improvement in arthritis severity at the end of the experiment as compared to arthritic non treated rats and rats treated with indo alone (Figure 1C). Regarding anti-nociceptive effects, treatment with vinpo either alone or in combination with both indo (ld or hd) showed a significant decrease in gait score as compared to non-treated rats (Figure 1D). Consequently, it is clear that, vinpo ameliorated the decrease in body weight, improved the change in ankle diameter and decreased the arthritis index as well as gait score in adjuvant arthritic rats.

\section{Behavioral changes in the swimming test}

Treatment with indo (ld or hd), vinpo alone or in combination with indo in both doses did not significantly affect latency time as compared to RA group. In addition, treatment with indo (ld) did not significantly affect swimming time while, treatment with indo (hd), vinpo alone and vinpo+indo either ld or hd results in significant decrease in swimming time by $38.79 \%, 71.13 \%, 68.96 \%$ and $71.54 \%$ respectively as compared to RA group. However, only vinpo either alone or in combination with 
Citation: Ali AA, El-Zaitony AS, Al-Haleem ENA (2016) Evaluation of Therapeutic Efficacy of Vinpocetine in Adjuvant Induced Arthritis Model in Rats. J Pain Manage Med 2: 115.

Page 4 of 10

indo (ld or hd) induced significant increase in the direction score as compared to RA group (Table 1).

\section{Effect on X-ray examinations}

As shown in Figure 2A-2G:

A: X-ray of normal rats showing no abnormalities,

B: X-ray of non-treated arthritic rats showing severe soft tissue edema (arrow), severe joint swelling, severe juxta-articular osteoporosis (circle) and very narrow joint space,

C: X-ray of indo (ld) treated arthritic rats showing moderate soft tissue edema (arrow), moderate joint swelling, severe juxta-articular osteoporosis (circle) and very narrow joint space,
D: X-ray of indo (hd) treated arthritic rats showing mild soft tissue edema and mild joint swelling, moderate juxta-articular osteoporosis and moderate narrow joint space,

E: X-ray of vinpo treated arthritic rats showing no soft tissue edema or joint swelling, moderate juxta-articular osteoporosis and moderate narrow joint space,

F: X-ray of vinpo+indo (ld) treated rats showing no soft tissue edema or joint swelling, moderate juxta-articular osteoporosis and moderate narrow joint space,

G: X-ray of vinpo+indo (hd) treated rats showing no soft tissue edema or joint swelling, mild juxta-articular osteoporosis with more improvement in the joint space.

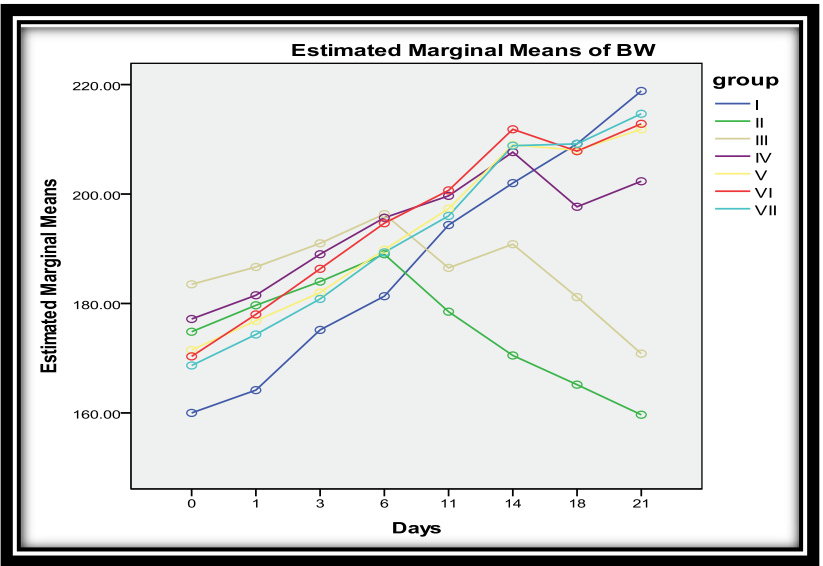

(A)

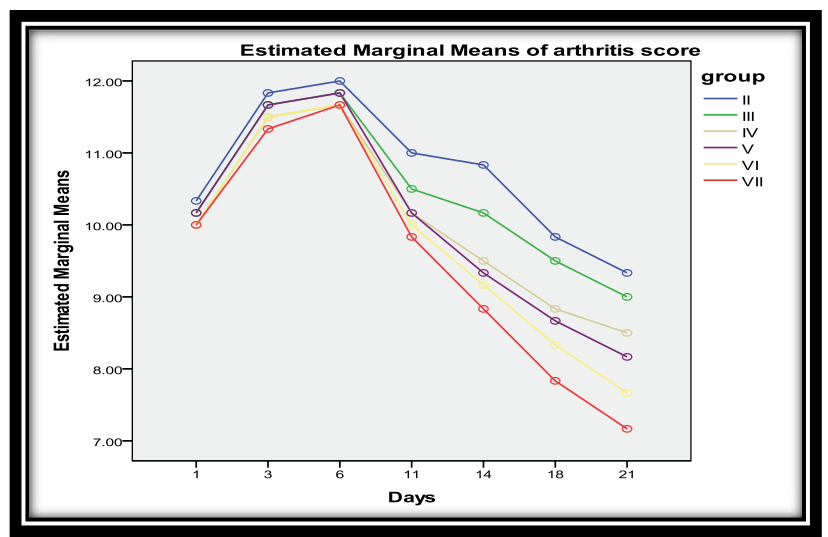

(C)

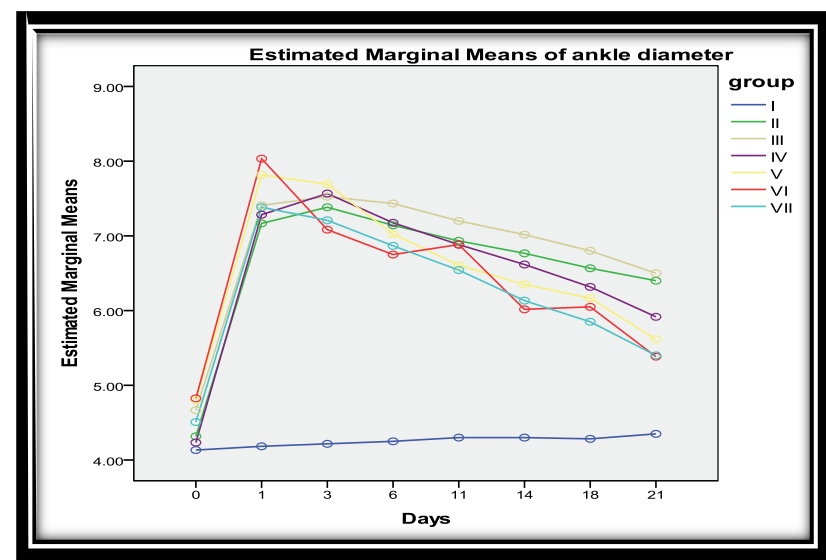

(B)

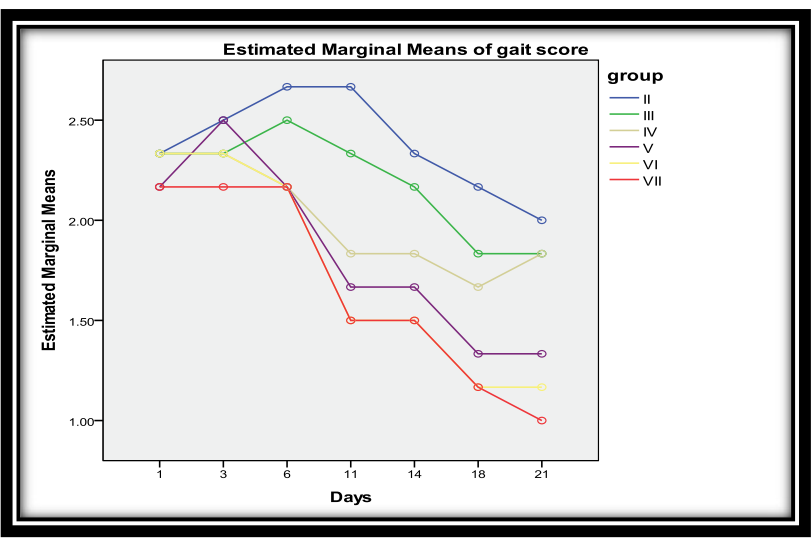

(D)

Data are represented as mean \pm SEM ( $n=8)$; Groups: I (control); II (RA); III (indo, Id); IV (indo, hd); V (vinpo); VI (vinpo+indo, Id); VII (vinpo+indo, hd). Statistical analysis was made by two-way ANOVA followed by Bonferroni test.

Figure 1: Effect of indomethacin (1 or $2 \mathrm{mg} / \mathrm{kg}$ P.O.) and/or vinpocetine (20 mg/kg P.O.) on body weight (A), ankle diameter (B), arthritis index (C) and gait score (D) in adjuvant arthritic rats.

\begin{tabular}{|c|c|c|c|c|c|c|c|}
\hline 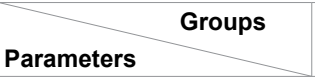 & Control & RA & RA+Indo (Id) & RA+Indo (hd) & RA+Vinpo & RA+Vinpo+Indo (Id) & RA+Vinpo+Indo (hd) \\
\hline Latency time (seconds) & $1.73 \pm 0.16$ & $2.16 \pm 0.16$ & $2.13 \pm 0.13$ & $2.16 \pm 0.16$ & $1.65 \pm 0.15$ & $1.63 \pm 0.15$ & $1.5 \pm 0.14$ \\
\hline Swimming time (seconds) & $19.0 \pm 0.96$ & $38.66 \pm 1.92^{\mathrm{a}}$ & $36.0 \pm 1.80^{\mathrm{a}}$ & $23.66 \pm 1.35^{b, c}$ & $11.16 \pm 0.9^{a, b, c, d}$ & $12.0 \pm 1.09^{\mathrm{a}, \mathrm{b}, \mathrm{c}, \mathrm{d}}$ & $11.0 \pm 0.89^{\mathrm{a}, \mathrm{b}, \mathrm{c}, \mathrm{d}}$ \\
\hline Direction score & $2.33 \pm 0.21$ & $1.83 \pm 0.16$ & $2.16 \pm 0.16$ & $2.33 \pm 0.21$ & $3.33 \pm 0.21^{a, b, c, d}$ & $3.5 \pm 0.22^{a, b, c, d}$ & $3.66 \pm 0.21^{\mathrm{a}, \mathrm{b}, \mathrm{c}, \mathrm{d}}$ \\
\hline
\end{tabular}

Data are represented as mean \pm SEM $(n=8)$; $a, b, c$ or $d$ : indicate significantly different from normal control, RA, RA+indo (ld or hd) respectively at $P<0.05$ using one-way ANOVA followed by Tukey-Kramer test for multiple comparison.

Table 1: Effect of indomethacin (1 or $2 \mathrm{mg} / \mathrm{kg}$ P.O.) and/or vinpocetine (20 mg/kg P.O.) on behavior of rats in the swimming test. 
Citation: Ali AA, El-Zaitony AS, Al-Haleem ENA (2016) Evaluation of Therapeutic Efficacy of Vinpocetine in Adjuvant Induced Arthritis Model in Rats. J Pain Manage Med 2: 115.

Page 5 of 10

\section{Effect on serum TNF-a}

Induction of RA by CFA $(0.1 \mathrm{ml}$ of $1 \mathrm{mg} / \mathrm{ml})$ induced significant increase in serum TNF- $\alpha$ level by $480.97 \%$ compared to normal control group, while treatment with indo (ld or hd), vinpo, vinpo+indo either ld or hd induced significant decrease in serum TNF- $\alpha$ level by $27.87 \%$, $43.48 \%, 54.88 \%, 67.305$ and $72.54 \%$ respectively compared to RA group (Table 2).

\section{Effect on serum IL-1 $\beta$}

Induction of RA by CFA $(0.1 \mathrm{ml}$ of $1 \mathrm{mg} / \mathrm{ml})$ significantly increased serum IL-1 $\beta$ level by $628.99 \%$ compared to normal control group,

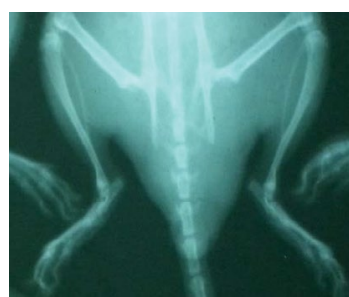

(A)

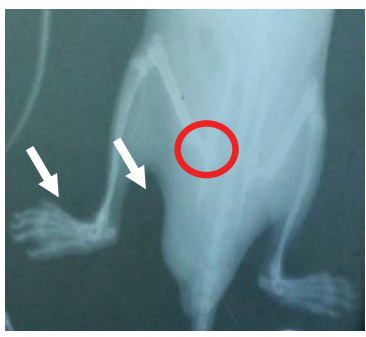

(C)

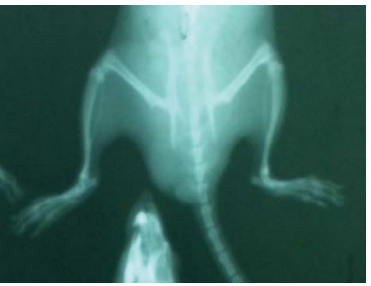

(E)

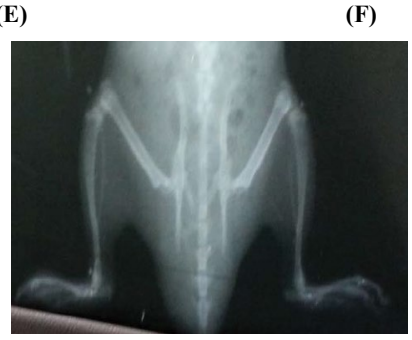

(G)

Figure 2: Effect of indomethacin (1 or $2 \mathrm{mg} / \mathrm{kg}$ P.O.) and/or vinpocetine (20 $\mathrm{mg} / \mathrm{kg}$ P.O.) on X-ray examinations of adjuvant arthritic rats. while treatment with indo (ld or hd), vinpo, vinpo+indo either ld or hd induced significant decrease in serum IL- $1 \beta$ concentration by $33.31 \%$, $49.62 \%, 61.89 \%, 71.86 \%$ and $76.80 \%$ respectively compared to RA group (Table 2).

\section{Neuclear Factor kappa-B (NF-кB)}

Statistical analysis of NF- $\kappa \mathrm{B}$ as area percentage of wet tissues showed that induction of RA by CFA $(0.1 \mathrm{ml}$ of $1 \mathrm{mg} / \mathrm{ml})$ induced a significant increase in the NF- $\kappa B$ content in hind paw tissues by $1203.53 \%$ as compared to normal control group. While, treatment with indo (ld), indo (hd), vinpo, vinpo+indo (ld) and vinpo+indo (hd) induced significant decrease in the NF- $\mathrm{kB}$ contents by $13.37 \%, 47.58 \%$, $62.15 \%, 80.82 \%$ and $89 \%$ respectively compared to RA group (Figure 3 ).

\section{Effect on serum total antioxidant capacity (TAC)}

Induction of RA by CFA $(0.1 \mathrm{ml}$ of $1 \mathrm{mg} / \mathrm{ml})$ induced significant decrease in serum TAC level by $83 \%$ as compared to normal control group, while treatment with indo (ld or hd), vinpo, vinpo+indo either ld or hd induced significant increase in serum TAC level by $72.29 \%$, $132.56 \%, 218.10 \%, 295.38 \%$ and $355.52 \%$ respectively as compared to RA group (Figure 4).

\section{Effect on brain monoamines contents}

Induction of RA by CFA did not significantly affect dopamine and norepinephrine contents while significantly decreased sertotonin content as compared to control group. Only treatment with vinpo alone or in combination with both indo (ld and hd) induced significant increase in dopamine content with percent of $1214 \%, 1274 \%$ and $1312 \%$ respectively as compared to control group. However, treatment of RA with indo (hd), vinpo, vinpo+indo both ld and hd significantly increased norepinephrine content by $291 \%, 424 \%, 954 \%$ and $1295 \%$ respectively as compared to RA group. In addition, treatment of RA with indo (hd), vinpo, combination of vinpo with indo (ld and hd) induced significant increase in serotonin content by 35\%, $100.2 \%$, 118.75 and $129 \%$ respectively as compared to RA group (Table 3 ).

\section{Photomicrographs of hind paw sections of rats stained by} Hematoxylin-Eosin stain (magnification $100 \mathrm{X}$ )

As shown in Figure 5A-5G:

A: Transverse section from paw of normal control rat showing normal histological structure of the covering epidermal ( $p$ ) and dermal (d) layers,

B: Transverse section from paw of non-treated arthritic rat, showing massive numbers of inflammatory cells infiltration $(\mathrm{m})$ in subcutaneous tissue (sc) with multiple adipoblasts,

C: Transverse section from paw of indo (ld) treated arthritic rat showing massive numbers of inflammatory cells infiltration $(\mathrm{m})$ in the subcutaneous tissue (sc),

D: Transverse section from paw of indo (hd) treated arthritic rat showing moderate numbers of inflammatory cells infiltration $(\mathrm{m})$ with adipoblasts in the subcutaneous tissue (sc) underneath the dermis (d),

\begin{tabular}{|c|c|c|c|c|c|c|c|}
\hline \begin{tabular}{|l} 
Groups \\
Parameters
\end{tabular} & Control & RA & RA+Indo (Id) & RA+Indo (hd) & RA+Vinpo & RA+Vinpo+Indo (Id) & RA+Vinpo+Indo (hd) \\
\hline Serum TNF- $\alpha$ (um/ml) & $20.08 \pm 0.53$ & $117.38 \pm 3.06^{a}$ & $84.66 \pm 2.08^{\mathrm{a}, \mathrm{b}}$ & $66.35 \pm 0.98^{a, b, c}$ & $52.96 \pm 1.18^{a, b, c, d}$ & $38.38 \pm 0.96^{\mathrm{a}, \mathrm{b}, \mathrm{c}, \mathrm{d}, \mathrm{e}}$ & $32.33 \pm 0.64^{\mathrm{a}, \mathrm{b}, \mathrm{c}, \mathrm{d}, \mathrm{e}}$ \\
\hline Serum IL-1 $\beta$ (um/ml) & $17.21 \pm 0.70$ & $125.46 \pm 3.01^{\mathrm{a}}$ & $83.66 \pm 1.92^{\mathrm{a}, \mathrm{b}}$ & $63.20 \pm 1.11^{a, b, c}$ & $47.81 \pm 1.03^{a, b, c, d}$ & $35.53 \pm 1.37^{\mathrm{a}, \mathrm{b}, \mathrm{c}, \mathrm{d}, \mathrm{e}}$ & $29.01 \pm 0.42^{\mathrm{a}, \mathrm{b}, \mathrm{c}, \mathrm{d}, \mathrm{e}}$ \\
\hline
\end{tabular}

Data are represented as mean \pm SEM $(n=8)$; $a, b, c$, d or e: indicate significantly different from normal control, RA, RA+indo (Id or hd) and vinpo respectively at $P<0.05$ using one-way ANOVA followed by Tukey-Kramer test for multiple comparison.

Table 2: Effect of indomethacin (1 or $2 \mathrm{mg} / \mathrm{kg}$ P.O.) and/or vinpocetine (20 mg/kg P.O.) on serum TNF- $\alpha$ and serum IL-1 $\beta$ levels in adjuvant arthritic rats. 
Citation: Ali AA, El-Zaitony AS, Al-Haleem ENA (2016) Evaluation of Therapeutic Efficacy of Vinpocetine in Adjuvant Induced Arthritis Model in Rats. J Pain Manage Med 2: 115.

Page 6 of 10

E: Transverse section from paw of vinpo treated arthritic rat showing moderate number of inflammatory cells infiltration $(\mathrm{m})$ and adipoblasts in subcutaneous tissue (sc) underneath the dermis (d),

F: Transverse section from paw of vinpo+indo (ld) treated arthritic rat showing small number of inflammatory cells infiltration $(\mathrm{m})$ in subcutaneous tissue (sc) underneath the dermis (d),

G: Transverse section from paw of vinpo+indo (hd) treated arthritic rat showing small number of inflammatory cells infiltration $(\mathrm{m})$ in subcutaneous tissue $(\mathrm{sc})$ underneath the dermis (d).

Photomicrographs of brain tissue sections stained by Hematoxylin-Eosin stain (magnification 100X)

As shown in Figure 6A-6G:

A: Brain section of normal control rat shows no histopathological changes,
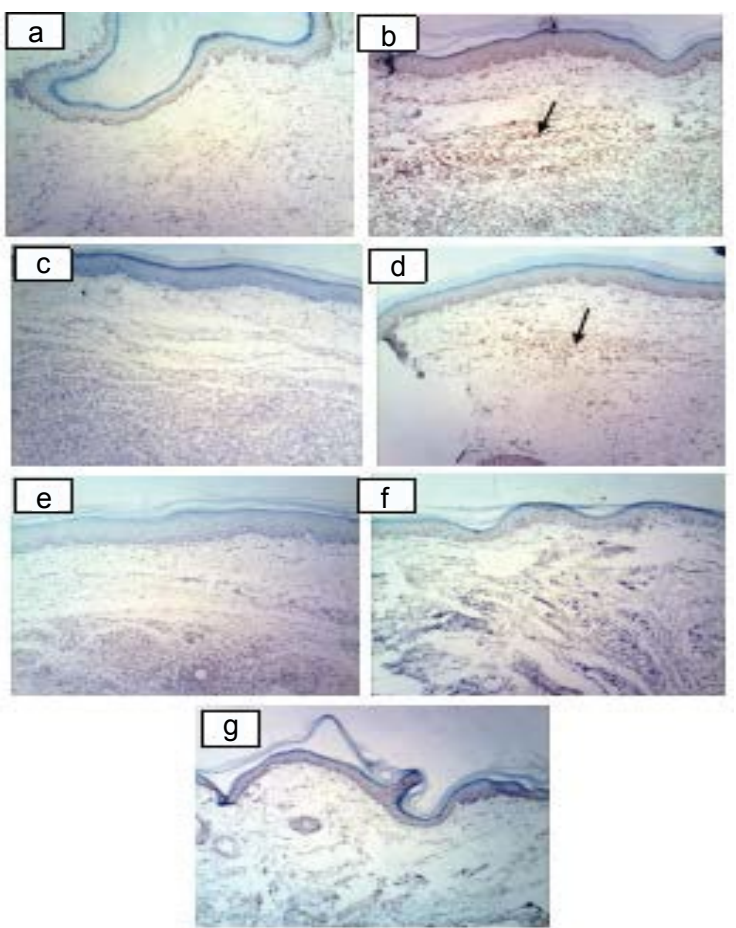

Figure 3: Effect of indomethacin (1 or $2 \mathrm{mg} / \mathrm{kg}$ P.O.) and/or vinpocetine (20 mg/ $\mathrm{kg}$ P.O.) on Nuclear factor kappa B (NF-KB) expression in the hind paw tissues by immunohistochemical staining (X100). a: Paw section of normal control rat shows almost negative immunostaining (no expression) for NF-KB, b: Paw section of arthritic non-treated rat shows strong positive immunoreactions (brown color), c: Paw section of indo (Id) treated rat shows strong positive immunoreactions, d: Paw section of indo (hd) treated rat shows moderate positive immunoreactions, e: Paw section of vinpo treated rat shows mild positive immunoreactions, f: Paw section of vinpo+indo (ld) treated rat shows weak positive immunoreactions, $\mathbf{g}$ : Paw section of vinpo+indo (hd) treated rat shows negative immunoreactions.
B: Brain section of arthritic non-treated rat shows multiple focal gliosis,

C: Brain section of indo (ld) treated rat shows necrosis of neurons and neuronophagia,

D: Brain section of indo (hd) treated rat shows necrosis of some neurons and neuronophagia,

E: Brain section of vinpo treated rat shows apparent normal brain tissue,

F: Brain section of vinpo+indo (ld) treated rat shows no histopathological changes,

G: Brain section of vinpo+indo (hd) treated rat shows no histopathological changes.

\section{Discussion}

Rheumatoid Arthritis is one of the most common inflammatory autoimmune diseases. It is characterized by persistent synovitis, systemic inflammation and production of autoantibodies [41]. CFA is widely used and considered to be the most effective adjuvant available. This model mirrors much of the pathology of RA; including hyperplasia of the synovial tissues, inflammatory infiltration of the joints, and destruction of bone and cartilage in the synovial joint [42]. In the present study, it was found that CFA injection induced significant paw edema, high arthritic score and significant elevation

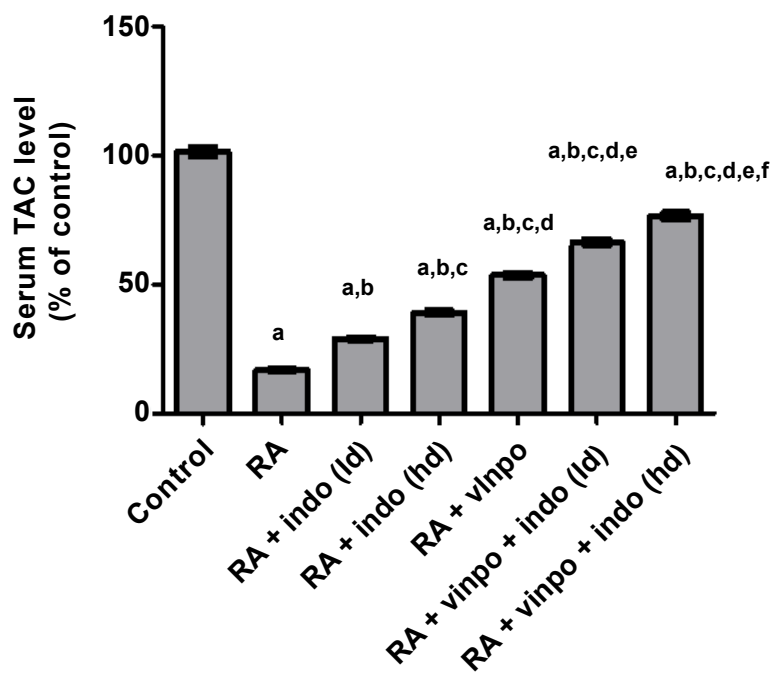

Data are represented as mean $\pm \operatorname{SEM}(n=8) ; a, b, c, d$, e or f: indicate significantly different from the corresponding control, RA, RA+indo (Id or hd),

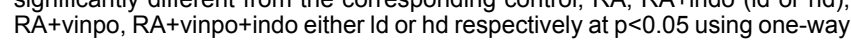
ANOVA followed by Tukey-Kramer test for multiple comparison.

Figure 4: Effect of indomethacin (1 or $2 \mathrm{mg} / \mathrm{kg}$ P.O.) and/or vinpocetine (20 $\mathrm{mg} / \mathrm{kg}$ P.O.) on serum TAC concentration in adjuvant arthritic rats.

\begin{tabular}{|c|c|c|c|c|c|c|c|}
\hline Parameters & Control & RA & RA+Indo (Id) & RA+Indo (hd) & RA+Vinpo & RA+Vinpo+Indo (Id) & RA+Vinpo+Indo (hd) \\
\hline Dopamine content ( $\mu \mathrm{g} / \mathrm{g}$ tissue) & $0.63 \pm 0.02$ & $0.56 \pm 0.04$ & $0.59 \pm 0.04$ & $1.58 \pm 0.09$ & $8.28 \pm 0.44^{\mathrm{a}, \mathrm{b}, \mathrm{c}, \mathrm{d}}$ & $8.66 \pm 0.38^{a, b, c, d}$ & $8.9 \pm 0.49^{a, b, c, d}$ \\
\hline Norepinephrne content ( $\mu \mathrm{g} / \mathrm{g}$ tissue) & $1.6 \pm 0.002$ & $1.57 \pm 0.007$ & $1.59 \pm 0.01$ & $6.14 \pm 0.39^{a, b, c}$ & $8.24 \pm 0.46^{a, b, c}$ & $16.42 \pm 0.76^{a, b, c, d, e}$ & $21.91 \pm 1.34^{a, b, c, d, e, f}$ \\
\hline Serotonin content ( $\mu \mathrm{g} / \mathrm{g}$ tissue) & $6.29 \pm 0.07$ & $4 \pm 0.13^{a}$ & $4.31 \pm 0.14^{a}$ & $5.45 \pm 0.38^{b}$ & $8.01 \pm 0.11^{a, b, c, d}$ & $8.75 \pm 0.26^{a, b, c, d}$ & $9.16 \pm 0.43^{a, b, c, d, e}$ \\
\hline
\end{tabular}

Data are represented as mean \pm SEM $(n=8) ; a, b, c, d$, e or f: indicate significantly different from normal control, RA, RA+indo (ld or hd), RA+vinpo, RA+vinpo+indo eithe Id or hd respectively at $\mathrm{P}<0.05$ using one-way ANOVA followed by Tukey-Kramer test for multiple comparison.

Table 3: Effect of indomethacin (1 or $2 \mathrm{mg} / \mathrm{kg}$ P.O.) and/or vinpocetine (20 mg/kg P.O.) on brain monoamines contents in adjuvant arthritic rats. 


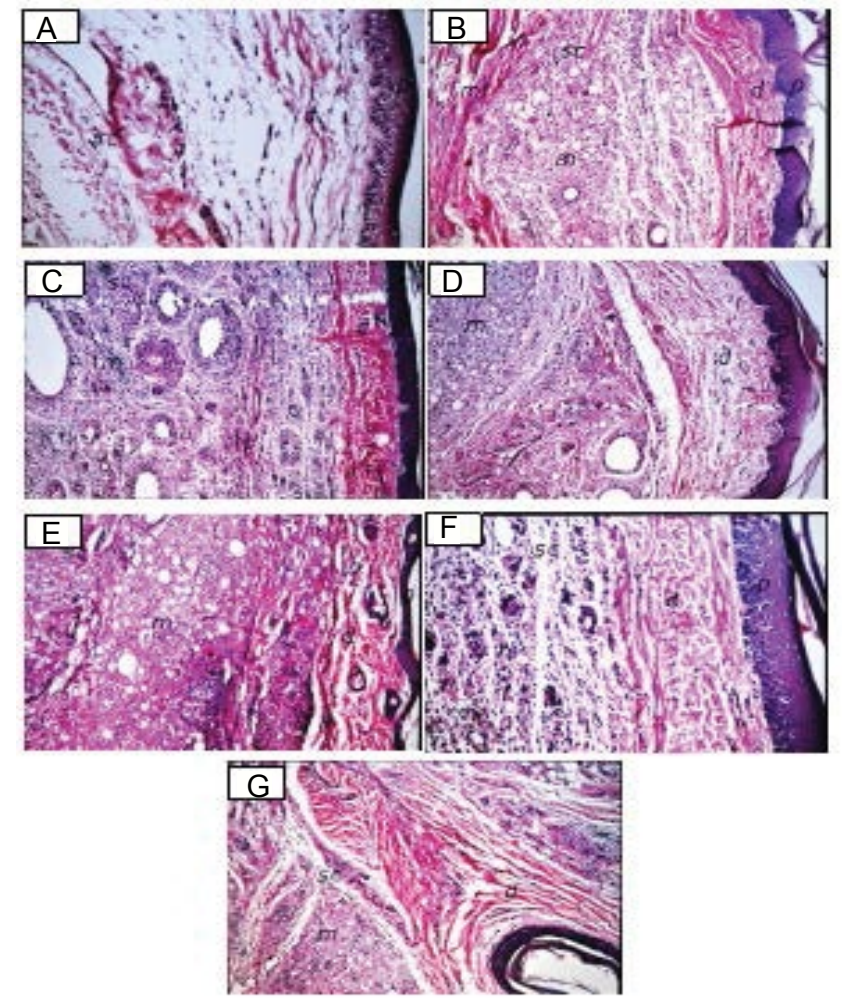

Figure 5: Effect of indomethacin (1 or $2 \mathrm{mg} / \mathrm{kg}$ P.O.) and/or vinpocetine (20 $\mathrm{mg} / \mathrm{kg}$ P.O.) on hind paw tissues examinations of rats.
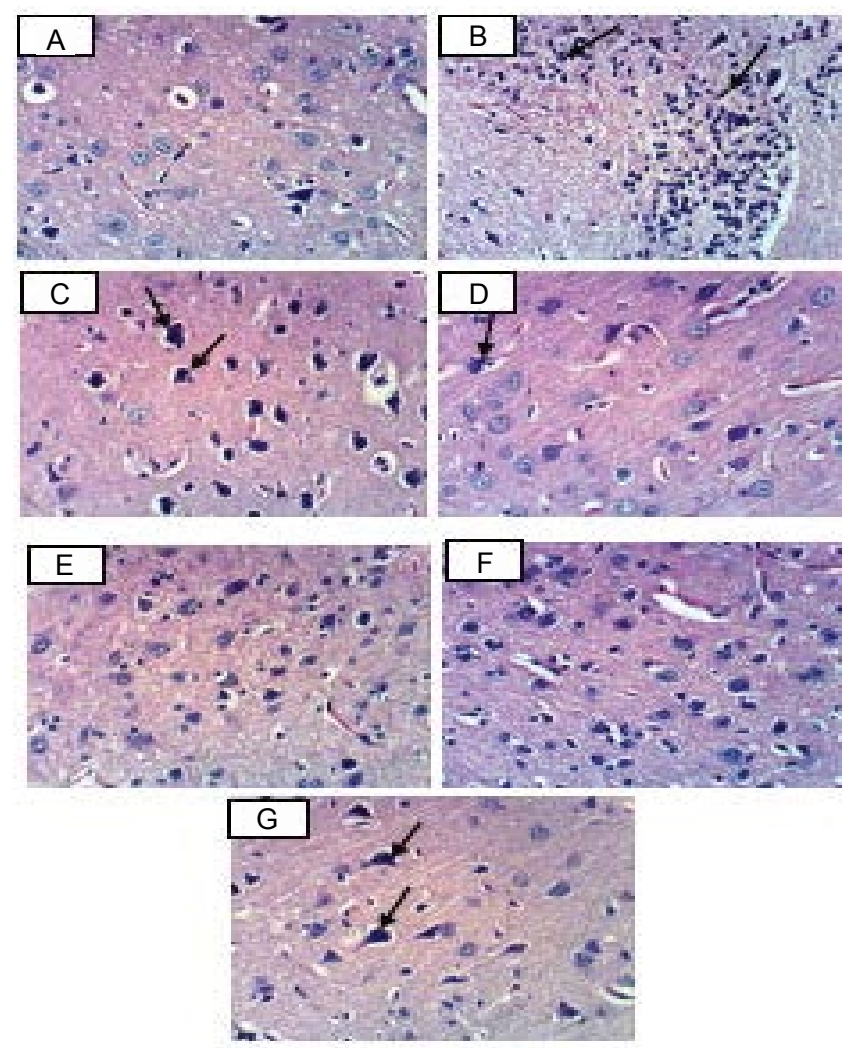

Figure 6: Effects of indomethacin (1 or $2 \mathrm{mg} / \mathrm{kg}$ P.O.) and/or vinpocetine (20 $\mathrm{mg} / \mathrm{kg}$ P.O.) on brain tissues examinations of rats. of TNF- $\alpha$ as compared to normal group which has been confirmed histopathologically by showing massive numbers of inflammatory cells and inflammation of the connective tissue.

Non-steroidal anti-inflammatory drugs are commonly prescribed in the management of RA to provide symptomatic relief but do not alter the course of the disease or prevent joint damage [19]. Indomethacin (which is one of the most commonly prescribed NSAID for management of RA symptoms) has the ability to enter the COX hydrophobic channel, competing with arachidonic acid for binding at the catalytic site and blocking the production of prostaglandins [43], but the use of NSAIDs in RA is currently limited due to high risk of gastrointestinal complications in addition to causing renal and cardiovascular complications like acute kidney failure, hypertension, electrolyte abnormalities, myocardial infarction, and stroke [19].

There is a great orientation about combination between chemical drugs and naturally occurring compounds in order to enhance the therapeutic potency and minimizing adverse effects. Vinpocetine is an alkaloid extracted from the periwinkle plant and has been used clinically for treating cerebrovascular disorders and improving memory [26]. It was demonstrating that it possesses a potent anti-inflammatory effect via direct inhibition of the IкB kinase complex [25], thereby can suppress inflammatory responses in vitro and in vivo [26]. Compared to traditional NSAIDs, vinpo has no known significant side effects thus making it an attractive alternate anti-inflammatory agent for long term use [27].

Accordingly, the present study was designed to evaluate the antiinflammatory effects of vinpo and to address its influence on the antiinflammatory effects of indo for treatment of adjuvant arthritis model induced in rats using CFA. For achievement of this purpose, body weight changes, ankle diameter and arthritic score were assessed as indicator of arthritis severity. Also, serum TNF- $\alpha$, IL- $1 \beta$ and tissue NF$\kappa \mathrm{B}$ were assessed as inflammation markers. Gait score was evaluated to assess the anti-nociceptive effect. These data were further confirmed by histopathological and X-ray examinations.

In the present study, it was found that indo (hd) significantly produced anti-arthritic effects by improving the changes of body weight, ankle diameter and arthritis score, which is supported by histopathological improvement of hind paw as compared to arthritic non-treated rats. These results are in agreement with the other results which confirmed the anti-arthritic effects of indo $(2 \mathrm{mg} / \mathrm{kg})$ mono therapy [29]. In addition, the present study revealed that, vinpo administration either alone or combined therapy with indo has a promising anti-arthritic effect through ameliorating the decrease in body weight and success to significantly decrease ankle diameter and arthritis score. In addition, the present results showed that vinpo has a promising anti-nociceptive effect by significantly decreasing the gait score. Results also showed that, vinpo treatment resulted in significant decrease in the swimming time and increase in the swimming direction score which can be attributed to its cognition enhancing effects [44].

In the current study, the radiographic examination of rats' hind paw from different groups showed that there was a severe soft tissue swelling along with severe joint space narrowing in the hind limb of arthritic non-treated rats which implies a bony destruction in arthritic conditions. This is in harmony with the previous findings which observe similar radiological changes in arthritis model [32]. However, vinpo treatment showed marked prevention against bony destruction by showing no soft tissue swelling and less narrowing of joint spaces which confirmed its anti-arthritic and anti-inflammatory effects. 
The present study also revealed that, there were significant high levels of TNF- $\alpha$ and IL-1 $\beta$ in the non-treated arthritic serum samples. These results are in accordance with the results which demonstrate that both IL- $1 \beta$ and TNF- $\alpha$ increased significantly in the serum of arthritic control rats [45]. This can be explained by the previous clinical studies which reported that the immune cells as activated T-lymphocytes and macrophages are the most important contributing factors in the pathogenesis of arthritis and the production of pro-inflammatory cytokines such as IL- $1 \beta$ and TNF- $\alpha$ is increased by the activated T cells and macrophages [46].

On the other hand, the present study was demonstrated that the serum samples from arthritic animals receiving indo treatment (especially at the high used dose) showed a significant drop in the levels of TNF- $\alpha$ and IL- $1 \beta$ by $43.48 \%$ and $49.62 \%$ respectively as compared to the non-treated group. These results are in accordance with the results of Kathem et al. [47], who found that administration of indo exerted a potent anti-inflammatory effect via significant reduction in serum TNF- $\alpha$ and IL- $1 \beta$.

The present study indicated that vinpo treatment alone (in a dose of $20 \mathrm{mg} / \mathrm{kg}$ ) caused a significant inhibition in the levels of TNF- $\alpha$ and IL$1 \beta$ by $54.88 \%$ and $61.89 \%$ respectively as compared to the non-treated group. This is in agreement with the previous clinical study done by Ruiz-Miyazawa et al. [48] which demonstrated that vinpo inhibits carrageenan-induced IL- $1 \beta$ and TNF- $\alpha$ production in the paw skin and spinal cord. The anti-inflammatory effect of vinpo can be explained on the basis that it inhibits TNF- $\alpha$ and LPS-induced up-regulation of pro-inflammatory mediators, including TNF- $\alpha$, IL- $1 \beta$ by targeting I $\kappa B$ kinase/NF- $\kappa \mathrm{B}$-dependent pathway via a direct inhibition of the ІкB kinase complex, thereby suppressing inflammatory responses in-vitro and in-vivo [25]. The percent of reduction in serum TNF- $\alpha$ and IL$1 \beta$ levels by administration of vinpo alone was $20.18 \%$ and $24.35 \%$ as compared to indo (hd) treated group.

Combination of vinpo with indo in the two used doses exerted a significant reduction in TNF- $\alpha$ and IL- $1 \beta$ levels comparable to nontreated RA and indo group. The combined treatment of vinpo with indo (ld) caused reduction of TNF- $\alpha$ and IL- $1 \beta$ levels by $67.35 \%$ and $71.86 \%$ respectively compared to RA group and by $42.15 \%$ and $43.78 \%$ respectively compared to indo (ld) group. The combined treatment of vinpo with indo (hd) caused reduction in TNF- $\alpha$ and IL- $1 \beta$ levels by $72.54 \%$ and $76.80 \%$ respectively as compared RA group and by $66.34 \%$ and $53.95 \%$ respectively as compared to indo (hd) group [47].

In this study, it was found that there was a marked elevation of NF$\mathrm{\kappa B}$ (p65) expression in the hind paw tissues of non-treated RA group by $1203.53 \%$ as compared to control group. These results are supported by Darwish et al. [49] who found that arthritic non-treated rats exhibited a significant increase in expression of the activated subunit of NF- $\kappa B$ (p65) in hind paw tissues. The results can be explained by Makarov [50] who indicated that, the pathogenesis of RA involves different inflammatory cascades including the transcription factor NF- $\kappa \mathrm{B}$ pathway, which plays a pivotal role in the inflammation and hyperalgesia associated with RA. Further explanation of NF- $\kappa B$ role in the pathogenesis of RA on the basis that NF- $\kappa B$ activation by IL- $1 \beta$ induced the gene expressions of matrix metalloproteinases (MMPs) that are major products of cytokine stimulated fibroblast-like synovial cells (FLS) and efficiently degrade the collagenous components of cartilage and bone, leading to the joint deformity and pain in the patient with RA [51].

The present study revealed that, the marked elevation of NF- $\mathrm{BB}$ expression in the hind paw of non-treated arthritic rats was significantly reduced upon treatment with indo (especially in the high used dose) by
$47.58 \%$ as compared to RA group. This finding is in accordance with other result indicated that a strong inhibition in NF- $\kappa B$ was found in indo treated CFA rats [52]. The ability of indo to inhibit NF- $\kappa B$ has been previously demonstrated using sulindac (NSAID that is structurally related to indo) [53]. These results suggested that inhibition of the NF$\mathrm{\kappa B}$ pathway may be involved in the anti-inflammatory properties of certain NSAIDs.

Regarding the effect of vinpo on the expression of NF- $\kappa \mathrm{B}$ in hind paw tissues, the present study found that RA group treated with vinpo alone showed a significant reduction of NF- $\mathrm{KB}$ expression by $62.15 \%$ as compared to non-treated RA group. This result is in accordance with other study in which vinpo attenuates carrageenan-induced $\mathrm{NF}-\kappa \mathrm{B}$ activation by targeting I $\kappa \mathrm{B}$ kinase (IKK) activity [46]. NF- $\kappa \mathrm{B}$ is a key transcriptional factor involved in regulating expression of pro-inflammatory mediators and playing a critical role in mediating inflammatory responses. Thus, the anti-inflammatory effect of vinpo can be driven by attenuation of NF- $\kappa B$ activity [54].

Combination of vinpo with indo at either dose levels resulted in a significant decrease in the expression of NF- $\mathrm{kB}$ in hind paw tissues comparable to non-treated RA and indo groups. The combined treatment of vinpo with indo in the two used doses significantly reduced NF- $\mathrm{KB}$ expression by $80 \%$ and $89 \%$ respectively as compared to RA group and by $63.40 \%$ and $79 \%$ respectively as compared to indo (hd) group. Thus, the inhibitory effects of vinpo on TNF- $\alpha$, IL- $1 \beta$ and NF- $\kappa B$ expression was significantly higher than that of indo, indicating that the anti-inflammatory effect of vinpo was higher than that of indo.

The present results showed that, induction of RA by CFA induced significant decrease in serum TAC by $83 \%$ as compared to normal control group. This is in agreement with $\mathrm{He}$ et al. [55] who confirmed that TAC activity decreased in the CFA model. This can be explained by several studies that suggest a role of oxidative stress in the pathogenesis of RA. Free radicals/ROS play an important role in chronic inflammation and pathogenesis RA. Free radicals/ROS produced in the course of cellular oxidative phosphorylation and repetitive cycles of hypoxia and re-oxygenation, along with oxidants produced by phagocyte cells such as macrophages and neutrophils, lead to chronic oxidative stress in the RA synovial microenvironment and the other tissues. This increased oxidative stress in synovial tissue and synovial fluid may be associated with increased disease activity, tissue damage and bone erosions in RA [56]

On the other hand, treatment with indo (especially in the high used dose level) significantly increased serum TAC as compared to non-treated RA group, which is in contrast with the results previously recorded that indo causes depletion of TAC [57]. This can be attributed to the difference in the used model and in the used dose levels. Moreover, vinpo alone therapy significantly increased serum TAC by $218 \%$ as compared to arthritic non-treated rats and by $36.7 \%$ as compared to indo (hd) treated rats. These results are in harmony with other results which found that vinpo inhibits carrageenan-induced peripheral decrease in antioxidant capacity level [46]. This can be attributed to its powerful antioxidant activities and ability to reduce oxidative stress and ROS [58]. It is worthy to note that, combination of vinpo with indo at either dose levels resulted in more significant increase in serum TAC levels.

Regarding the effect on brain neurotransmitters contents, the obtained results indicated that induction of arthritis caused a significant decrease in brain serotonin contents. This is in accordance with the previous study [59] which found that brain serotonin level in arthritic animals decreased significantly against with normal. There are several proposed mechanisms explaining low brain serotonin level 
Citation: Ali AA, El-Zaitony AS, Al-Haleem ENA (2016) Evaluation of Therapeutic Efficacy of Vinpocetine in Adjuvant Induced Arthritis Model in Rats. J Pain Manage Med 2: 115.

Page 9 of 10

in RA including the decrease in tryptophan (precursor of serotonin) availability in the brain due to its increased additional catabolism in inflammatory cell during arthritis which may contribute to the decreased serotonin synthesis at this region [60]. The other possible mechanism of the decreased brain 5-HT level in RA has been illustrated due to the peripheral immune activation, such as that seen with inflammatory diseases and induces release of IL- $1 \alpha$, IL-1 $\beta$, IL- 6 , and TNF- $\alpha$ which can reach brain via different pathways including stimulation of peripheral afferent nerve fibers which in turn activate the microglia to produce cytokines in the brain [61]. In addition to the regions in the blood brain barrier (BBB) which allow access of peripheral inflammatory mediators to the brain. Once cytokine signals reach the brain, they can interact with every pathophysiologic domain relevant to depression. However, arthritis induction does not significantly affect dopamine or norepinephrine contents in the brain while, vinpo treatment either alone or in combination with indo in the two used dose levels caused significant increase in serotonin content as well as, vinpo caused a significant increase in dopamine and norepinephrine contents. This is in harmony with the previous studies demonstrated that vinpo increases the levels of neurotransmitters involved in memory functions, namely norepinephrine and dopamine in addition to its main role in antagonize depression that associated to the arthritis disease.

In the present results, histopathological examination of hind paw tissues of non-treated animals showed massive numbers of inflammatory cells infiltration with multiple adiboplasts which are in agreement with other results [62]. On the other hand, abnormalities alleviated by administrating vinpo indicate its potent anti-inflammatory activity. Moreover, histopathological examination of brain tissues of non-treated rats showed multiple focal gliosis, necrosis of neurons and neuronophagia which can be explained by the previous study suggested that circulating immune complexes can elicit a neuro-inflammatory response in the brain [63]. Another explanation of brain inflammation in RA is attributed the presence of brain cytokines such as TNF- $\alpha$ which mediated by regulating the expression of cyclooxygenase (COX) enzymes (mainly COX-2) and generation of prostanoids [64].

Finally, it is obvious that vinpo has a potent anti-arthritic, antiinflammatory and anti-noceceptive effects which may be to some extent higher than that of indo. Also, it has a potent anti-depressant activity. In addition, it is safe, non-toxic and has no harmful adverse effects or drug interactions. So, the use of vinpo in treatment of arthritis may be a promising due to its potency and its ability to improve arthritis associated depression and mood disturbances which is a major complication especially in the late stages and in elderly patients due to inability to perform their daily activities.

\section{Conclusion}

Vinpocetine has a potent anti-inflammatory and anti-nociceptive effects which may be equal to or higher than that of indo. It also potentiates the anti-inflammatory effects of indo. In addition, RA associated neurological disorders especially depression and brain inflammation are improved by vinpo administration. Further studies are required to evaluate the possibility of clinical application.

\section{Acknowledgements}

Authors acknowledge Dr. Kawkab A Ahmed, Professor of pathology, Faculty of Vetrinary Medicine, Cairo University for her help in the histopathological examinations part in this work.

\section{Conflict of interest}

Authors declare that they have no conflicts of interest to disclose.

\section{References}

1. Woolf AD, Pfleger B (2003) Burden of major musculoskeletal conditions. Bull World Health Organ 81: 646-656.

2. Haroon N, Aggarwal A, Lawrence A, Agarwal V, Misra R (2007) Impact of rheumatoid arthritis on quality of life. Mod Rheumatol 17: 290-295.

3. Creemers MCW, van de Putte LB (2004) Rheumatoid arthritis - the clinical picture. In: Isenberg DA, Madison PJ, Woo P, Klars D, Breedveld FC (eds) Oxford textbook of rheumatology. 3rd edn. Oxford: Oxford University Press.

4. Currey HLF (1988) Essentials of rheumatology. 2nd edn. London: Churchill Livingstone.

5. Hess A, Axmann R, Rech J, Finzel S, Heindl C, et al. (2011) Blockade of TNF-a rapidly inhibits pain responses in the central nervous system. Proc Natl Acad Sci U S A 108: 3731-3736.

6. Mclnnes IB, Schett G (2011) The pathogenesis of rheumatoid arthritis. N Engl J Med 365: 2205-2219.

7. Brennan FM, Mclnnes IB (2008) Evidence that cytokines play a role in rheumatoid arthritis. J Clin Invest 118: 3537-3545.

8. Gravallese EM, Harada Y, Wang JT, Gorn AH, Thornhill TS, et al. (1998) Identification of cell types responsible for bone resorption in rheumatoid arthritis and juvenile rheumatoid arthritis. Am J Pathol 152: 943-951.

9. Bendele A (2001) Animal models of rheumatoid arthritis. J Musculoskele Neuronal Interact 1: 377-385.

10. Joe B, Wilder RL (1999) Animal models of rheumatoid arthritis. Mol Med Today 5: 367-369.

11. Wooley PH (2004) The usefulness and the limitations of animal models in identifying targets for therapy in arthritis. Best Pract Res Clin Rheumatol 18 : 47-58.

12. Pearson CM (1956) Development of arthritis, periarthritis and periostitis in rats given adjuvants. Proc Soc Exp Biol Med 91: 95-101.

13. Thirumal M, Bharathi RV, Kumudhaveni B, Kishore G (2013) Anti-arthritic activity of chloroform extract of Barringtonia acutangula (L) Gaertn. leaves on wister rats. Der Pharmacia Lettre 5: 367-373.

14. Vashist H, Gupta A, Jindal A, Jalhan S (2012) Animal models for arthritis- A review. Int $\mathrm{J}$ of Adv in Pharmac Research 2: 20-25.

15. Mohan T, Verma P, Rao DN (2013) Novel adjuvants \& delivery vehicles for vaccines development: a road ahead. Indian J Med Res 138: 779-795.

16. Grosser T, Smyth E, FitzGerald GA (2011) Anti-inflammatory, antipyretic, and analgesic agents; pharmacotherapy of gout. In: Brunton LL, Lazo JS,Parker $\mathrm{KL}$, editors. Goodman \& Gilmans's the pharmacological basis of therapeutics. 12th edn. Vol. 34. New York: McGraw-Hill; p. 959-1004.

17. Hardman JG, Limbird LE, Gilman AG (2001) Goodman and Gilman's The Pharmacological Basic of Therapeutics. 10th edn, New York: The McGraw-Hill Companies Inc.

18. Huskisson EC, Taylor RT, Burston D, Chuter PJ, Hart FD (1970) Evening indomethacin in the treatment of rheumatoid arthritis. Ann Rheum Dis 29: 393-396.

19. Scheiman JM, Hindley CE (2010) Strategies to optimize treatment with NSAIDs in patients at risk for gastrointestinal and cardiovascular adverse events. Clin Ther 32: 667-677.

20. Szatmari SZ, Whitehouse PJ (2003) Vinpocetine for cognitive impairment and dementia. Cochrane Database Syst Rev: CD003119.

21. (2002) Vinpocetine. Monograph. Altern Med Rev 7: 240-243.

22. Vora CS, Gujar KN (2013) Vinpocetine: Hype, Hope and Hurdles towards neuroprotection. Asian J Pharm Res Dev 1: 17-23.

23. Bagoly E, Fehér G, Szapáry $L$ (2007) The role of vinpocetine in the treatment of cerebrovascular diseases based in human studies. Orv Hetil 148: 1353-1358.

24. Khulbe P, Juyal V (2011) Vinpocetine: A Step towards memory enhancement. Int J Pharmaceut Res Dev 2: 99- 108

25. Jeon KI, Xu X, Aizawa T, Lim JH, Jono H, et al. (2010) Vinpocetine inhibits NFkappaB-dependent inflammation via an IKK-dependent but PDE-independent mechanism. Proc Natl Acad Sci U S A 107: 9795-9800. 
Citation: Ali AA, El-Zaitony AS, Al-Haleem ENA (2016) Evaluation of Therapeutic Efficacy of Vinpocetine in Adjuvant Induced Arthritis Model in Rats. J Pain Manage Med 2: 115.

Page 10 of 10

26. Lee JY, Komatsu K, Lee BC, Miyata M, O'Neill Bohn A, et al. (2015) Vinpocetine Inhibits Streptococcus pneumoniae-Induced Upregulation of Mucin MUC5AC Expression via Induction of MKP-1 Phosphatase in the Pathogenesis of Otitis Media. J Immunol 194: 5990-5998.

27. Liu RT, Wang A, To E, Gao J, Cao S, et al. (2014) Vinpocetine inhibits amyloidbeta induced activation of NF-KB, NLRP3 inflammasome and cytokine production in retinal pigment epithelial cells. Exp Eye Res 127: 49-58.

28. Seideman P, von Arbin M (1991) Cerebral blood flow and indomethacin drug levels in subjects with and without central nervous side effects. $\mathrm{Br} \mathrm{J}$ Clin Pharmacol 31: 429-432.

29. Jakhetia V, Khatri P, Patel R, Badgujar L, Pandey A (2011) The protective effect of ethanolic extract of Sida Tiagii Bhandari seeds against complete freund's adjuvant induced experimental animal model of rheumatoid arthritis. Pharmacologyonline 1: 861-872.

30. Banji D, Pinnapureddy J, Banji OJ, Saidulu A, Hayath MS (2001) Synergistic activity of curcumin with methotrexate in ameliorating Freund's Complete Adjuvant induced arthritis with reduced hepatotoxicity in experimental animals. Eur J Pharmacol 668: 293-298.

31. Helyes Z, Pintér E, Németh J, Kéri G, Thán M, et al. (2001) Anti-inflammatory effect of synthetic somatostatin analogues in the rat. Br J Pharmacol 134: 1571 1579.

32. Vijayalaxmi A, Bakshi V, Begum N (2015) Anti-Arthritic and Anti Inflammatory Activity of Beta Caryophyllene against Freund's Complete Adjuvant Induced Arthritis in Wistar Rats. J Bone Rep Recom 1: 2-9.

33. Kim KW, Shin YS, Kim KS, Chang YC, Park KK, et al. (2008) Suppressive effects of bee venom on the immune responses in collagen-induced arthritis in rats. Phytomedicine 15: 1099-1107.

34. Ramprasath VR, Shanthi P, Sachdanandam P (2006) Therapeutic effects of Semecarpus anacardium Linn. nut milk extract on the changes associated with collagen and glycosaminoglycan metabolism in adjuvant arthritic Wistar rats. Chem Biol Interact 162: 43-52.

35. Bush KA, Kirkham BW, Walker JS (2001) The kappa-opioid agonist asimadoline, alters cytokine gene expression in adjuvant arthritis. Rheumatol (Oxford) 40: 1013-1021.

36. Ali AA, Hamed MR, El-Sayed M (1992) Effect of protein Malnutrition on postnatal Neurobehavioural Response to Drugs. M.Sc. Thesis, Faculty of Pharmacy, Cairo University, Egypt; p. 59-160.

37. Koracevic D, Koracevic G, Djordjevic V, Andrejevic S, Cosic V (2001) Method for the measurement of antioxidant activity in human fluids. J Clin Pathol 54 356-361.

38. Buchwalow I B, Boecker W (2002) Immunohistochemistry: Basics and Methods. 1 st edn. New York: Springer.

39. Abdel-Salam OME, Salem NA, El-Shamarka ME, Ahmed NA, Hussein JS et al. (2013) Cannabis-induced impairment of learning and memory: effect of different nootropic drugs. EXCLI J 12:193-214.

40. Banchroft JD, Stevens A, Turner DR (1996) Theory and practice of histological techniques. 4th edn. New York: Churchil Livingstone.

41. Scott DL, Wolfe F, Huizinga TW (2010) Rheumatoid arthritis. Lancet 376: 1094 1108.

42. Chou L, Wang J, Chang P, Hsieh Y (2011) Hyaluronan modulates accumulation of hypoxiainducible factor-1 alpha, inducible nitric oxide synthase, and matrix metalloproteinase- 3 in the synovium of rat adjuvant-induced arthritis model. Arthritis Res Ther 13: R90.

43. Reese J, Dey SK (2002) Cyclooxygenases. In: Kazazian HH Jr, Klein G, Moser $\mathrm{HW}$, eds. Encyclopedia of molecular medicine. $5^{\text {th }}$ edn. New York: John Wiley \& Sons, Inc. pp. 961-965.

44. Patyar S, Prakash A, Modi M, Medhi B (2011) Role of vinpocetine in cerebrovascular diseases. Pharmacol Rep 63: 618-628.

45. Shah SU, Jawed H, Awan SI, Anjum S, Simjee SU (2013) The anti-arthritic and immune-modulatory effects of NHAG: a novel glucosamine analogue in adjuvant-induced arthritis. Biomed Res Int 2013: 487610.

46. Falgarone G, Semerano L, Rullé S, Boissier MC (2009) Targeting lymphocyte activation to treat rheumatoid arthritis. Joint Bone Spine 76: 327-332.

47. Kathem RA, El-Denshary E, Nada SA, El-Yamany M, Mansour DF, et al (2014) Antinociceptive and Anti-Inflammatory Activity of Bovine Milk-Derived
Lactoglobulin: Study of Combined Effect with Tramadol or Indomethacin. Glob J Pharmacol 8: 444-456.

48. Ruiz-Miyazawa KW, Zarpelon AC, Pinho-Ribeiro FA, Pavão-de-Souza GF Casagrande R, et al. (2015) Vinpocetine reduces carrageenan-induced inflammatory hyperalgesia in mice by inhibiting oxidative stress, cytokine production and NF-KB activation in the paw and spinal cord. PLoS One 10 e0118942.

49. Darwish SF, El-Bakly WM, Arafa HM, El-Demerdash E (2013) Targeting TNF-a and NF-KB activation by bee venom: role in suppressing adjuvant induced arthritis and methotrexate hepatotoxicity in rats. PLoS One 8: e79284

50. Makarov SS (2001) NF-kappa B in rheumatoid arthritis: a pivotal regulator of inflammation, hyperplasia, and tissue destruction. Arthritis Res 3: 200-206.

51. Niu X, Chen G (2014) Clinical biomarkers and pathogenic-related cytokines in rheumatoid arthritis. J Immunol Res 2014: 698192.

52. Gao LN, Feng QS, Zhang XF, Wang QS, Cui YL (2016) Tetrandrine suppresses articular inflammatory response by inhibiting pro-inflammatory factors via NF$\mathrm{KB}$ inactivation. J Orthop Res.

53. Yamamoto $Y$, Yin MJ, Lin KM, Gaynor RB (1999) Sulindac inhibits activation of the NF-kappaB pathway. J Biol Chem 274: 27307-27314.

54. Rothwarf DM, Karin M (1999) The NF-kappa B activation pathway: a paradigm in information transfer from membrane to nucleus. Sci STKE 1999: RE1.

55. He YH, Zhou J, Wang YS, Xiao C, Tong Y, et al. (2006) Anti-inflammatory and anti-oxidative effects of cherries on Freund's adjuvant-induced arthritis in rats. Scand J Rheumatol 35: 356-358.

56. Ediz L, Hiz O, Ozkol H, Gulcu E, Toprak M, et al. (2011) Relationship between anti-CCP antibodies and oxidant and anti-oxidant activity in patients with rheumatoid arthritis. Int J Med Sci 8: 139-147.

57. Ferrari CK (2012) Effects of xenobiotics on total antioxidant capacity. Interdiscip Toxicol 5: 117-122.

58. Herrera-Mundo N, Sitges M (2013) Vinpocetine and a-tocopherol prevent the increase in DA and oxidative stress induced by 3-NPA in striatum isolated nerve endings. J Neurochem 12: 233-240.

59. Mehboob KM, Najma S, Arayne MS, Darakhshan SM (2011) Decreased Brain Serotonin Level in Adjuvant Induced Arthritic Rats. Int J Toxicol Pharmacol Res 3: $9-13$.

60. Bell C, Abrams J, Nutt D (2001) Tryptophan depletion and its implications for psychiatry. Br J Psychiatry 178: 399-405.

61. Shelton RC, Miller AH (2011) Inflammation in depression: is adiposity a cause? Dialogues Clin Neurosci 13: 41-53.

62. Matsukawa M, Ogawa M, Nakadate K, Maeshima T, Ichitani Y, et al. (1997) Serotonin and acetylcholine are crucial to maintain hippocampal synapses and memory acquisition in rats. Neurosci Lett 230: 13-16.

63. Teeling JL, Carare RO, Glennie MJ, Perry VH (2012) Intracerebral immune complex formation induces inflammation in the brain that depends on Fc receptor interaction. Acta Neuropathol 124: 479-490.

64. Fuggle NR, Howe FA, Allen RL, Sofat N (2014) New insights into the impact of neuro-inflammation in rheumatoid arthritis. Front Neurosci 8: 357 